\title{
Understanding Socio-Technical Change: Towards a Multidisciplinary Approach
}

\author{
Edouard J. Simon, Monique Janneck, and Dorina Gumm \\ University of Hamburg, Department of Informatics, Germany \\ \{simon, monique.janneck, gumm\}@informatik.uni-hamburg.de
}

\begin{abstract}
Designing information technology involves the responsibility to be aware of the possible consequences that arise from its use. This can hardly be achieved from a single discipline's viewpoint. The paper describes an approach that is currently being developed to support a multidisciplinary perspective on the reciprocity between society and computers. It is a work in progress that is being developed by a network of scholars located mainly at the University of Hamburg, Department of Informatics.
\end{abstract}

Keywords: Ethics, Socio-Technical Change, Multidisciplinarity, Innovation, Reciprocity

\section{Innovation as an Ethical Challenge}

Social Informatics deals with the interrelation between human action and computers [1] - a reciprocity that influences not only our view on labour and economic development but also the very way we communicate and cooperate. Information technology (IT) is increasingly setting the pace and direction of what is supposed to be innovation. This is true at a global level where politicians are forced to rethink their notion of national interest and to cooperate internationally. It is also true at a national and local level, where IT helps in developing new markets, destroys whole lines of industry, and allows for undreamed of productivity increase resulting in unheard of unemployment. Finally, it is true at a personal level, shaping new social behaviour and deepening a new, digital divide.

But speaking only of technology changing our world would be a technological determinism that has been discarded quite some time ago [1]. Technology provides us with the means to do different things, or things differently, than we could do without it. It is up to us to decide what we want to do and which instruments we need. The ethical challenge intrinsically tied to social change is part of the

Please use the following format when citing this chapter:

Simon, E. J., Janneck, M., Gumm, D., 2006, in IFIP International Federation for Information Processing, Volume 223, Social Informatics: An Information Society for All? In Remembrance of Rob Kling, eds. Berleur, J., Numinen, M. I., Impagliazzo, J., (Boston: Springer), pp. 469-479. 
innovation process. Nevertheless, innovation is often treated as an appendix to technological research and development. Some consider innovation to be unpredictable, stating that no one could tell what benefit might arise from new technologies. Some assume that embedding technological artefacts in society is a different task than inventing them, involving different actors. Thus IT researchers and developers would not need to bother about the social consequences [2]. Some even regard technological change as a market-driven process which is (and should be) beyond social or political intervention.

To hold these views means to actually negate the very possibility of innovation in terms of social progress. The meaning of innovation is separated from the process of research and development and delegated to specialised professionals, like politicians or even left to the market. Without an understanding of how research and development affects, or at least might impact, society there can be no progress. Understanding is the first step in any approach to change the world for better - at least it should be.

\section{The Need for a Multidisciplinary Approach}

The widespread use of IT is a complex phenomenon, promoting economical, political, social, and behavioural change at all levels of human action. It is thus a phenomenon that can only be understood from a multidisciplinary point of view. Such a multidisciplinary approach brings in questions that deal with the selfconception of academic research. The questions are posed from the different viewpoints of the involved disciplines, such as: What exactly are we looking at? What do we want to find out? What will all the research eventually be good for? In other words, at least two fundamental issues have to be addressed in a multidisciplinary approach:

- Make clear what our subject is. What looks like a technological artefact to one researcher will appear like a set of behavioural constraints to another. A third will neither perceive how it works nor how it affects behaviour, but will recognise the social and economic interaction that leads to the creation of it. What one studies as a black box will be obviously transparent to another, and vice versa. The subject of a profession is constructed according to its particular self-conception which is not necessarily (and most often actually not) compatible among professions. A multidisciplinary approach can help to build bridges: by providing conceptual links that mediate between different perceptions of similar phenomenons; and by developing a conceptual framework that acts as a map that can help to locate different academic approaches within an integrative heuristic approach.

- Make clear what our cognitive interest is. Computer Sciences and related disciplines aim at changing - that is, somehow improving - working and living conditions. For many other disciplines - like social science or psychology - this involves a shift, from mere contemplation about how things are related, towards a more constructive and targeted reasoning. Since, there is little a profession can do on its own to find out about what actually is an improvement from a society's 
point of view, only a few professionals are aware of the consequences that arise from their efforts to change the world. This is where a multidisciplinary approach becomes necessary. Knowledge about the interplay of social action and information technology is not only favourable to, but a necessity for, independent academic research. Without it we are not able to know whether we aim in the right direction and thus know nothing about innovation. The improvement of living conditions is not only a highly contingent process, but also, for many reasons, there can be no impartial definition of what is an improvement. Therefore, a multidisciplinary approach should allow for normative issues, statements about the quality of technological improvements in terms of social progress.

\section{Mikropolis - a Multidisciplinary Approach to Understand Socio-Technical Change}

Mikropolis - derived from Mikroelektronik (german for microelectronics) and polis - is the name of a multidisciplinary research initiative and approach. Mikropolis aims at describing, analysing, and understanding the interplay between information technology development and social and political action [3].

The Mikropolis approach is not designed to replace or even complement existing theoretical examinations of socio-technical systems. We use the metaphor of a travel guide to describe its scope [4]: It provides a map that allows for orientation within the landscape of theories about technological innovation. In some cases, the conceptual attribution is quite obvious while sometimes there is a need for further investigation before a theory can be mapped to our framework.

In the following paragraphs, we first describe the Mikropolis Initiative, a group of researchers from different disciplines. Then we present the basic elements of the Mikropolis approach itself.

\subsection{The Mikropolis Initiative: Bringing the Disciplines Together}

The Mikropolis initiative consists of an interdisciplinary group of researchers working mainly at the Department of Informatics at the University of Hamburg, complemented by researchers from other universities and also practitioners (e.g. consultants). The disciplines represented in our group include Informatics, Information Systems, Political Science, Psychology, Social Science and Environmental Informatics.

Concerned with various topics in the fields of Information Systems, Human Computer Interaction, Computer Supported Cooperative Work (CSCW) and Learning (CSCL) and Virtual Organisations, we share a common understanding that designers and developers of software and information technology need to take into account the social and organisational conditions as well as the consequences of technology use.

We work on the Mikropolis approach because it serves as a tool to explain phenomena we observe in our respective application domains or even as a guide for 
socio-technical design decisions. In our various research areas and projects we take different perspectives on the Mikropolis approach:

- Theoretical perspective: We aim for strengthening the Mikropolis approach theoretically, relating it to existing theoretical frameworks and models of sociotechnical interdependencies, as well as organisational theories and models of human behavior.

- Empirical perspective: We seek to ground the Mikropolis approach in our empirical work, e.g. case studies of virtual organisations, using it as an analytical instrument and testing its explanatory and predictive power.

- Consulting perspective: We are interested in using the Mikropolis approach as a guide to advise organisations with respect to IT development and use.

\subsection{The Mikropolis Approach: Constructing a Multidisciplinary Conceptual Framework}

The Mikropolis approach has its origins in higher education. It has been developed since the late 90s at the Department of Informatics at the University of Hamburg and has been modified and enhanced by students and researchers. From a theoretical perspective we use our approach for educational purposes. As a didactical framework it is being used by several scholars and has recently been published by the German Federal Agency for Civic Education [5, 6]. With regard to the empirical and consulting perspective it is already in use by an IT-consultant who is part of the Mikropolis network.

We adopt a multidisciplinary perspective by integrating concepts from different professions into a conceptual framework. This framework may be characterized as a template consisting of specific cognitive patterns that are familiar across disciplines.

The Mikropolis approach takes a close look at the actors and their interests and motives. There is a distinction between the micro- and macro-level of analysis, which corresponds to social, political, or economic contexts of interaction. In addition to this structural view there is a longitudinal perspective allowing for the analysis of temporal aspects. Last but not least, there are basic assumptions about the interrelation between human action and information technology - in other words, the analysis of reciprocity can be considered as the core issue of our approach.

The Mikropolis approach must not be understood as a theory. Rather it serves as a heuristic approach to analyse the interplay between social action and information technology from different disciplinary perspectives and to act as a translator. For indepth explanations of the phenomena studied, it is necessary to 're-embed' the multidisciplinary discourse into a discipline's theoretical framework.

\subsubsection{Reciprocity as an analytical perspective}

Reciprocity operates as the basic analytical perspective in our approach. In terms of individual IT use and development, reciprocity means on one hand the interrelating process of formalising human action and 'translating' it into computer executable routines and re-embedding those routines into the social context on the other hand. Since this process involves a generalising description of context-specific action, 
which is then somehow transferred back into a context, we call it the reciprocity of decontextualisation and recontextualisation.

On an organisational level we make a distinction between those organisations using and those developing IT. It should be emphasised that this distinction is an analytical one, since many organisations using information technology develop or at least customise the products they use in-house, and those developing are themselves users of IT. Therefore we accent the complex system of different actors that are involved in advancing information technology, involving, for example globally operating software vendors, publicly funded research institutions, or IT-related R\&D-sections of a larger organisation.

The relation between these actors can be characterized as a sectoral system of innovation [7]. The interaction between organisations using IT and the IT-related sectoral innovation system is used for the analysis of the interplay between development and use of IT, which can be characterized as either demand-driven or technology-driven.

\subsubsection{The structural perspective}

We make an analytical distinction between the micro-context and the macro-context of socio-technical systems. This allows for a view on organisational aspects of computerisation and the societal influences on these, as well as the impact of ITrelated organisational change on economy, society, culture, and politics.

The micro perspective focuses on the interplay between IT and its embedding into organisational contexts. IT is used and developed, in specific contexts of interaction, where people work together and communicate, consisting of a specific set of rules, tradition, and history that it emerged from.

The macro perspective focuses on the socio-political context in which the organisations are themselves embedded, consisting of social and political norms as well as cultural habits and values and economic pressures in a globalised world.

\subsubsection{The temporal perspective}

The longitudinal analysis of socio-technical contexts provides a deeper insight into patterns of the development and adoption of technologies. The history of such a context can be described as a chronology of decisions for certain technological options, leaving others behind. The development of socio-technical systems can thus be seen as a reduction of contingency in IT-usage based on the status quo, which, in turn, stimulates the future development of IT.

Successful technological innovations form a historically determined path of technology development and the associated organisational development. Tracing this path of technology use shows that 'history matters' [8]. Decisions of technology use (or non-use) set the course for the future, subsequently enabling further development or preventing possible alternative practices. Decisions to take one way or another are not merely a matter of rational choice, but also of cultural beliefs and emotions (e.g., technology friends and foes) as well as of power, defining winners and losers. Thus, technology becomes a matter of scientific and ethical discourse.

Analysing the technology use path is important to assess what ways future design decisions might pave. Of course, future developments cannot be predicted using the 
Mikropolis approach, but knowing crucial switches of the past helps to appraise future paths of development.

\subsubsection{Actors}

Looking at socio-technical systems makes it inevitable to take an analytical view on actors. Their specific interests, tasks, and activities and the technology used to support them are at the center of the socio-technical system.

The Mikropolis approach integrates different concepts of actors focusing different roles, like computer users [9] or participants of market transactions ('homo oeconomicus'). Such concepts highlight aspects of intential behaviour that are important from their point of view, but fail to provide realistic assumptions adequately reflecting the complexity of human interaction. Therefore, we rely on a concept of actors that does not presume any role or context but instead provides categories that inform us about the specific abilities, perceptions, and preferences, which, analytically speaking, form an actor's identity [10].

Within the Mikropolis approach, we look at micropolitical processes - i.e. actors' strategies to gain influence and power within their institutional and hierarchical framework [11] - to explain and interpret the actions of individuals and groups. Another important tool is the analysis of motives, missions, and ideals.

Furthermore, social psychological concepts, findings concerning group behavior, and intergroup relations might inform the Mikropolis approach. This is a prospect for our future work.

\section{The Mikropolis Approach as a Framework for the Design of Virtual Organisations - A Case Study}

Our approach has proven to be useful for examining the inter-relation between human action and IT design in a research project on the socio-technical design of virtual organisations. In this section, we will present the case study of a virtual network of freelancers to exemplify how we use the Mikropolis approach as a heuristic model that can inform us about social issues that affect the use of IT. On the other hand, we use this case study to reveal weaknesses of our approach and advance it.

We developed and customised a groupware system for a network of freelancers in a participatory design process $[12,13,16]$ within the scope of a research project focusing on the sustainable development of virtual networks of freelancers, as a new and rapidly spreading form of virtual organisations.

The network was founded in 1997 by freelance IT and management consulting professionals to exchange experiences, knowledge, and work results. It offers its members vocational training and the opportunity to get involved in several occupational working groups or to meet potential clients via the network's contacts. Today about 15 members belong to the community. It is completely self-organised by its members without formal hierarchies or roles, thus relying on its members' involvement and commitment. Financial resources are scarce. 
In the past, several project management systems were tested within the network before we got involved as a research group. However, with each of them, the usage turned out to be unsatisfactorly low. The network members blamed this on the respective software, which they regarded as unsuitable for their tasks.

We therefore decided to implement another groupware system, which was to be continually adapted due to the networks' needs, involving as many of the network members as possible in the process. A systematic evaluation was carried out to investigate the network's requirements for software support. Semi-structured interviews were chosen as an appropriate method to grasp the subjective views of the community members. Additionally, this approach allows for addressing specific topics and comparing between interviews [14]. We conducted three group interviews with a total of twelve community members.

The interviews were audio-taped, with the interviewee's permission and transcribed verbatim, resulting in over 200 pages of interview-transcripts. Data analysis was carried out following the three steps of paraphrasing, generalisation, and reduction suggested by Mayring [15]. In the first step, the respective units of analysis (usually singular phrases) are paraphrased to reach a uniform level of speech. In the next step, the paraphrased expressions are generalised on a higher level of abstraction to enhance comparability (generalisation). Thirdly, synonymous or correspondent expressions are omitted or combined (reduction).

Furthermore, we observed the network's system usage while working with two core members acting as representatives to discuss their usage experiences, analyse usage problems, and plan further developments for about 18 months. We conducted regular workshops every two or three months with these network representatives, applying scenario techniques, and using mock-ups for elaborating design ideas [16].

Even though the network members stressed the general necessity of communicating online and agreed that the platform was suitable for their needs, the intensity of use still turned out to be very low after approximately a year and a half, frustrating the small number of active users. Since we suspected social and organisational reasons for this, we used the Mikropolis approach to analyse the network situation. A detailed account of this analysis is given by Finck et al. [17].

The following analytical tools supplied by the Mikropolis approach turned out to be helpful: At the micro level we looked at the changes the freelancers had to face with regard to their work organisation when they started to collaborate within their network and identified conflicts that might have interfered with their usage. This addressed issues like different experiences with individual desktop applications that were no longer applicable to a shared web-based workspace, or preferences for different ways of organising work that had to be negotiated within the network.

Tracing the path of technology use showed that decisions regarding IT support had seldom been discussed with a substantial number of network members, but rather been made by individual members who were especially competent and interested in IT use. This led to confusion and insecurity within other members regarding the continuity of IT use, reducing their motivation to use the system. Analysing the actors' interests, actions, and motives showed a clear area of conflict between the ideal of equal, non-hierarchical cooperation that was propagated within the network and its actual practices. We found that decision-making processes were clearly dominated by certain core members, showing hierarchical structures. 
Furthermore, we observed tension concerning the network's main purposes and goals. These purposes varied from mainly social exchange and support to economic interests, such as improved possibilities for aquisition and a stronger market position. An economic orientation, however, raises issues of competition between individual network members, presumably hindering both social exchange and true cooperation. The implicit competition within the network is heightened by the rough economic situation on the macro level that the freelancers are currently facing.

We concluded that these discrepancies between the network's goals, ideals, and motives on the one hand and their daily practices on the other hand accounted for the low intensity of use that we observed on the network platform.

In this vague collaborative setting, concrete occasions and incentives for use are rare. Furthermore, due to the economic pressures the freelancers are facing, it is rather advisable for them to be careful when investing scarce resources such as time and ideas into the network. This especially applies to providing (economically relevant) content to the shared groupware system. This analysis has several consequences for future socio-technical development: Regarding software support, we need to check whether functionalities supporting equal and intense cooperation are truly suitable for the network's needs. Regarding organisational development, we consider it necessary to explicate, clarify, and, if necessary, change current visions, expectations, and goals within the network.

\section{IT-Usage in the Medical Care System: A View on Strategies}

In a study on IT usage for medical care from a Mikropolis perspective [18], strategies concerning the promotion of IT related innovations were examined. The study was carried out by a member of the Mikropolis network and was based on empirical findings collected during his work as an IT-consultant.

The examination of strategies concerning IT-support of organisational procedures led to the interesting finding that there is a difference between individual strategies of the various actors involved and an overall strategy, usually set by the management. Moreover, the findings suggested that the latter is usually merely wishful thinking, since the complex interaction of different strategic orientations will most likely render the outcome unpredictable. This is true, at least when the perceptions, preferences, and resources of all stakeholders within the organisation are not taken into account. It might even be necessary to look at external actors, as long as these have relevant preferences and are able to raise a sufficient amount of resources to interfere in the process. This conclusion was based on the results of four different IT-related projects: acquisition of a specialised documentation system, external quality assurance in a surgical ward, introduction of a general surgery planning system, and security orientation of the IT department.

All four projects were analysed, with regard to the distribution of power among the stakeholders, the strategy legitimated by the management, and a collective strategy resulting from an (implicit or explicit) consensus between the actors involved. In two projects a collective strategy could not be achieved, since the preferences of some of the fractions involved directly opposed the legitimated 
strategy. In these cases the outcome reflected the distribution of power among the fractions. In the other projects, a consensus was achieved either through a change of preferences or by finding a solution that met the needs of all stakeholders.

In our analysis we could identify three resources of power that had an impact on the degree in which actors influenced the results: Institutions, knowledge, and involvement in realisation. Following [10] we use the term 'institutions' for all kinds of more or less stable settings that the actors agree on, like, for example organisational structures, contracts, or cultural habits. There is no doubt that the management of a hospital has most of the institutional power, being able to control almost all contracts and thus being in control of all of the material resources. The second source of power turned out to be knowledge. Mainly the IT department, but also the health professionals could in some cases enforce their position, simply because no one else was able to argue it. In fact, technical knowledge turned out to be one of the most important resources in terms of influence on the result. Nearly equally important was to be actively involved in realising the socio-technical infrastructures, whether socially - as users who could either use or boycott the system - or technically where the IT department was in the position to push or to slow down the development.

As already mentioned, the actors staking their claims were mainly the management, the IT department, and the medical staff. Especially the head physicians played an important role in promoting new technical features, while the IT department usually had the last word on what happened and how it happened. In one project, external software developers developed an interface between two software systems, one of which was preferred by a medical department while the other was pushed by the IT department. It showed that the preferences of the interface developers - namely to get further jobs - had a significant impact on the outcome of the project, even though they were not directly involved in it. Because maintaining the interface turned out to be quite costly and time consuming both departments involved soon agreed on switching to one of the systems.

This case study showed that the analytical concept of actors, as used in the Mikropolis approach, turned out to be useful to explain social phenomena, which would not be visible when only taking into account the measures taken to watch over the implementation of previously agreed-on specifications. It seems to allow, at least partially, for a prediction of the outcome of IT-projects involving complex actor constellations. It has shown the importance of looking at micro-political processes. But there is still work to be done to refine the analytical toolset and take a closer look at strategic processes.

\section{Conclusions}

In this paper, we introduced the Mikropolis approach as a framework for understanding and shaping socio-technical change in a multidisciplinary setting. We addressed different applications and perspectives of the Mikropolis approach: theoretical, didactical, empirical and consulting. Furthermore, by means of two case 
studies we presented one possibility to use the Mikropolis approach, for analysing specific settings in which socio-technical problems and questions arise.

The Mikropolis approach is work in progress. It needs to be refined and strengthened theoretically, and we need more empirical evaluations to test its usefulness. In order to do so, we plan to take a closer look at the German health care system, where socio-technical innovation is a fundamental issue to civil society, reflecting the need for the advancement of high-tech products and procedures, thereby taking into account the requirements of highly complex organizations and infrastructures as well as institutional entwinements between a multiplicity of different public and private actors. Moreover, ethical and moral issues affect trends and decisions. For many of the activities going on in this sector, IT has become a crucial factor and more often than not a precondition for future development. Analysing those activities, from a Mikropolis perspective, is our prospect for future work.

We are going to expand the Mikropolis initiative to include other researchers and practitioners interested in reflective socio-technical development and design and will gladly get into contact with anyone interested in the field.

\section{References}

1. Rob Kling. What is social informatics and why does it matter? D-Lib Magazine, 5(1):1-25 (1999).

2. Edsger W. Dijkstra. On the cruelty of really teaching computing science. Comm. of the $A C M, 32(12): 1398-1404$ and 1414, (1989).

3. Krause, D., Rolf, A., Christ, M., Simon, E. (in preparation): Wissen, wie alles zusammenhängt - Das Mikropolis-Modell als Orientierungswerkzeug für die Gestaltung von Informationstechnik in Organisationen und Gesellschaft. Published in: InformatikSpektrum (2006).

4. Arno Rolf. Reiseführer für Informatik und Gesellschaft. fifF-Jahrbuch, (2005).

5. Arno Rolf. Von der Theoriearbeit zur Gestaltung. In Wissensgesellschaft. Neue Medien und ihre Konsequenzen. Bundeszentrale für politische Bildung, Bonn (2004).

6. Arno Rolf, Informationstechnologien in Organisationen und Gesellschaft, In: Medienpädagogik: 'Wissensgesellschaft' (2005).

7. Franco Malerba, editor, Sectoral Systems of Innovation. Concepts, Issues and Analyses of Six Major Sectors in Europe. Cambridge University Press, 2004.

8. Georg Schreyögg and Jörg Sydow, editors. Strategische Prozesse und Pfade. Managementforschung 13. Wiesbaden: Gabler, (2003).

9. Rob Kling and Roberta Lamb. Reconceptualizing users as social actors. In: information systems research. MIS Quarterly, 27(2): 197-235, June 2003.

10.F. W. Scharpf, Games Real Actors Play: Actor-Centered Institutionalism in Policy Research, Boulder, 1997.

11. O. Neuberger, Mikropolitik: Der alltägliche Aufbau und Einsatz von Macht in Organisationen. Enke, Stuttgart, 1995.

12. Finck, M., Janneck, M. Hospitality in Hosting Web-Based Communities: Two Case Studies. In: Kommers, P., Isaias, P. (eds), Web Based Communities 2005: Proceedings of the IADIS International Conference Web Based Communities 2005 (2005), pp. 327-330.

13. Janneck, M., Finck, M., Appropriation and Mediation of Technology Use in Stable SelfOrganised Online Communities. In: Kommers, P., Isaias, P., Goikoetxea, A. (eds): Web 
Based Communities 2006: Proceedings of the IADIS International Conference Web Based Communities 2006, (2006) pp. 149-156.

14. Kvale, S, InterViews: An introduction to qualitative research interviewing. Sage, Thousand Oaks, CA, 1996.

15. Mayring, P., Qualitative Inhaltsanalyse: Grundlagen und Techniken, 8. edn. Weinheim: Beltz, 2003.

16. Janneck, M., Finck, M., Obendorf, H., Participatory Design: An Issue for Web-Based Community Development?! In: Kommers, P., Isaias, P., Goikoetxea, A. (eds): Web Based Communities 2006: Proceedings of the IADIS International Conference Web Based Communities 2006, (2006) pp. 274-277.

17. Finck, M., Janneck, M., Rolf, A., Techniknutzung zwischen Kooperation und Konkurrenz -- eine Analyse von Nutzungsproblemen. In: Lehner, F., Noehsekabel, H., Kleinschmidt, P. (Hrsg.): Multikonferenz Wirtschaftsinformatik 2006, (2006) pp. 636-376

18. Drews, P., IT-Strategie im Krankenhaus: Akteure, Prozesse und Inhalte. Diploma Thesis, Institute for Information Systems, University of Hamburg, 2004 (unpublished). 